REVISTA DE DERECHO UNED, NÚM. 28, 2021

\title{
ÉTICA Y DEBERES EN LOS NUEVOS CÓDIGOS DEONTOLÓGICOS. UNA VISION DESDE ITALIA
}

\section{ETHICS AND DUTIES IN THE NEW DEONTOLOGICAL CODES. A VIEW FROM ITALY}

Paola B. Helzel

LUIGI CARAVITA*

Universidad de Calabria

"La ética ha recogido el nombre más expresivo de la deontología"

Sumario: I. Status quaestionis. II. Origen y evolución de la deontología. III. La naturaleza del 'deber' de los códigos deontológicos y la ética profesional. IV. Reglas deontológicas: funciones y calificación jurídica. V. Deontología forense. VI. El Código deontológico forense europeo.

Resumen: De un tiempo a esta parte proliferan una serie de códigos deontológicos ue establecen los deberes y directrices éticos atribuibles al ejercicio de una determinada profesión. Para entender bien este fenóieno es necesario reconstruir el origen y la posterior evolución de la deontología, la naturaleza del 'deber' de los códigos deontológicos y la ética profesional, la funcion y calificación de las reglas deontológicas. La naturaleza de las normas deontológicas no ha sido un tema pacífico. Supone volver al debate sobre la relación entre derecho y moral. En el presente artículo se analiza la posición de la jurisprudencia italiana en relación con las propias consideraciones al respecto de esta cuestión que realizan los códigos deontológicos de la abogacía española, de la abogacía italiana, así como el de los abogados europeos. 
Abstract: For a while now, a series of deontological codes have been appearing. These codes establish the duties and ethical guidelines that certain profesional must respect in the exercise of their profession. For a proper understanding of this phenomenon, it is necessary to remember the origin and subsequent evolution of deontology, the nature of the 'duty' of deontological codes and professional ethics, and the function and qualification of deontological rules. The nature of ethical standards has not been a peaceful issue. It means returning to the debate on the relationship between law and morality. This article analyzes the position of the Italian jurisprudence in relation to the own considerations regarding this issue made by the deontological codes of the Spanish legal profession, of the Italian legal profession, as well as that of European lawyers.

Palabras clave: ética, códigos deontológicos, abogacía

Keywords: ethics, deontological codes, advocacy

Recepción original: 08-04-2021

Aceptación original: 15-09-2021

\section{STATUS QUAESTIONIS}

En los últimos años ha surgido una verdadera "emergencia deontológica" que ha determinado la proliferación, en las organizaciones de las relaciones sociales, de toda una serie de códigos deontológicos y de autodisciplina, es decir, de toda una serie de reglas que los operadores de los sectores específicos adoptan de forma autónoma, para regular el ejercicio de las actividades que se realizan ${ }^{1}$. Esto ha colocado a la deontología bajo la lupa, convirtiéndola en un fenómeno de especial interés.

Una causa probable de esto se podría identificar en la necesidad, reconocida por muchos, de tener que superar la ambigua vaguedad en la que parece haberse convertido la figura en la actual sociedad. En este contexto, la deontología profesional representa el conjunto de reglas y de "principios que rigen los particulares comportamientos no de carácter técnico del profesional, implementados o relacionados de algún modo con el ejercicio de la profesión y

* Los párrafos 1,2,3 han sido redactados por P.B.Helzel, mientras que los párrafos 4,5,6 han sido redactados por L. Caravita.

Cfr., QuADRI, E., Il codice deontologico medico ed i rapporti tra etica e diritto, in “Responsabilità civile e previdenziale”, nn. 4-5, 2002, p. 926. 
la pertenencia al grupo profesional" 2 . Y es gracias a la deontología que las distintas profesiones pueden acreditarse ante las sociedades en las que operan, adoptando formas de autodisciplina que van desde un simple juramento hasta el propio código deontológico.

De esta manera, el conjunto de reglas que 'ordenan' la conducta del profesional y al mismo tiempo califican al grupo organizado al que pertenece, constituyen "una ética según el rol" que tiene la tarea de cumplir, principalmente, dos funciones, desde un punto de vista externo, representa un detector de los particulares deberes y privilegios que a lo largo del tiempo se han atribuido social e institucionalmente a su actividad; desde el plano interno, sin embargo, consta de un conjunto de directrices encaminadas a definir los problemas prácticos y dilemas éticos inherentes al ejercicio de la profesión ${ }^{3}$. La deontología profesional, en otros términos, representa una identidad a través de una ética, sustentando, eso es, "el proceso de construcción de una imagen, más o menos correspondiente a la realidad, mediante la cual cada profesión trata de hacer socialmente aceptable el disfrute de ciertos privilegios obligándose a sí misma a realizar determinados deberes sociales y superar el egoísmo de los propios profesionales" 4 .

En definitiva, tiene la tarea de armonizar el estado de excepción representado por la ética del rol profesional con la normalidad social y, al mismo tiempo, de frenar mediante la autodisciplina la posibilidad de excesos en el ejercicio del propio poder técnico por parte de los profesionales, los que de otro modo no serían comprobables para los profanos mediante diferentes tipos de herramientas ${ }^{5}$.

De aquí es fácil comprender cómo la deontología se refiere a los deberes del profesional, a las obligaciones a las que debe corresponder en su actuación profesional. El deber, en este contexto, implica una especie de obligación moral, en virtud de la cual el profesional no actúa para ejecutar una orden externa o para evitar una sanción,

2 LEgA,C., Deontologia forense, Giuffrè, Milano 1975, p. 1.

3 Al respecto remitirse a GUISÀN, E., Ética y deontologìa, in "Educatìon y Biblioteca", n. 98, 1999, p.46.

4 FebBrajo, A., L'etica dell'avvocato come progetto professionale, in "Sociologia del diritto", n. 3, 1985, p. 13.

5 Para profundizar al respecto remito a FERNÁNDEZ,A. G., Ética y deontologìa, in "Education y Biblioteca", n. 159, 2007, p.72, en el que A. sostiene que "la deontología es un intento de conciliar lo formal, las generalidades modelizadas de una profesión, y lo vital, las situaciones concretas de cada uno de los miembros pertenecientes a dicha profesión, llevando así los presupuestos de la ética individual a una colectiva». 
sino reconociendo en sí mismo el deber de actuar de acuerdo a una regla de conducta ${ }^{6}$.

En este sentido, la referencia a la deontología implica una actitud bastante formal, una determinada conducta a seguir con respecto a otra a evitar. En otras palabras, es como si la deontología se cubriera con la «dignidad de un velo vagamente piadoso y sentimentalmente generoso cuando faltan argumentos fuertes y racionales» ${ }^{7}$. Es como si asumiera las características del imperativo categórico de la memoria kantiana, un "se debe" hacer así y no de otra manera. Y es en esta excepción donde la deontología se arraiga en la opinión pública hasta el punto de ser considerada como una disciplina ajena a cualquier otro saber, un lugar en sí misma.

De hecho, no es así, como lo demuestra la fuerte necesidad - reconocida por muchos - de referirse a él cada vez con más frecuencia. Dicho esto, es muy necesario, - para una mayor comprensión-, partir del significado etimológico de la palabra y luego volver sobre sus etapas fundamentales hasta la actualidad. El término deontología tiene claramente un origen griego, ya que deriva de la unión de dos palabras deon ( $\delta$ cov deber) y logos ( $\lambda$ oyos discurso), por lo tanto, un discurso sobre el deber, que en un principio parece referirse a una ciencia que no da respuestas, pero que se limita a ofrecer una lista de deberes y obligaciones. Y, entonces, si la deontología es una ciencia o un tratado del deber, es necesario - de manera preliminar- comprender qué es el deber, y sobre todo cuál sea el significado etimológico de este término y qué orígenes filosóficos implica además de los meramente jurídicos ${ }^{8}$. Habitualmente el término deontología se apoya en el aspecto que se refiere a la correcta realización de un trabajo por parte del profesional, cuando, por el contrario, sería más útil resaltar "cómo el mismo profesional debe ser un 'hombre' en el mejor ejercicio de la profesión" 9 . La cultura de los deberes, por tanto, entendida como modelo de humanidad, todavía sirve hoy como guía para el mundo occidental ${ }^{10}$. El término 'deber' en italiano se usa tanto como sustantivo como verbo y deriva del latín 'debere', una palabra compuesta, formada por 'de' que significa

6 Cfr., SALA, R., Forme dell'obbligo tra diritto e morale: il codice deontologico degli infermieri nella discussione di etica pubblica, in "Io Infermiere", n. 3, 2008, p.18.

7 CARsillo, R., Deontologia: tra etica e diritto, Aracne, Roma 2011, p.10.

8 Respecto al argumento remito a P.B. Helzel, Per una teoria generale del dovere, Cedam, Padova 2016.

9 CARsillo, R., op. cit., p. 11.

10 Para mayor información respecto a la cultura de los deberes remito a CALABRò, G.P.- Helzel, P. B.,Il sistema dei diritti e dei doveri, Giappichelli, Torino 2007. 
'de' y 'habere' que significa tener, por tanto, asume el significado de "haber recibido algo de alguien y, por tanto, adeudado ${ }^{11 "}$.

El significado original del término deber es precisamente el de "lo que debe hacerse", es decir, lo que uno está obligado a hacer o lo que las circunstancias exigen ${ }^{12}$. Por tanto, podríamos considerar el deber como una acción que se ajusta a un orden racional o una norma. En el sentido de acción conforme a un orden racional, la noción de deber se origina en los Estoicos, para quieneses es deber (kathêkon) toda acción o comportamiento tanto del hombre como de las plantas y animales que se ajusta al orden racional del todo ${ }^{13}$.

Diógenes Laercio, por ejemplo, definió deber "aquello cuya elección puede justificarse racionalmente" ${ }^{14}$, y añade que deber son aquellas acciones "que la razón aconseja realizar como honrar a los padres, hermanos, la patria y llevarse bien con los amigos". En este sentido, resulta evidente como originalmente la doctrina del deber se fundó en la norma de "vivir según la naturaleza", que de hecho es la norma de conformarse al orden racional del todo ${ }^{15}$. Posteriormente, Kant retomará la noción de deber tal como la desarrollaron los estoicos, convirtiendo, sin embargo, la conformidad al orden racional del todo, conforme a la ley de la razón.

11 La entrada "deber" está tomada del Diccionario Enciclopédico Italiano “Treccani”, Roma 1970, p.186.

12 Sobre el tema s.v. también lo que está expuesto por FinNIS, J.M., Legge naturale e diritti naturali, (1992), trad. it., Giappichelli, Torino 1996, p. 326, en el que A. observa cómo, de hecho, "los filósofos y moralistas encuentran conveniente el sustantivo" obligación "para referirse a una amplia gama de conceptos: que hay cosas, dentro del alcance de nuestro poder de hacer o no hacer, que (independientemente de lo que deseemos) debemos hacer (pero no porque estemos obligados a hacerlo); que hay cosas que es nuestro deber hacer, que es ilícito o vergonzoso no hacer.

13 Abbagnano, N. (a cura), Dovere, v., in "Dizionario di Filosofia", Torino 1971, p. 266; en cuanto al significado del deber para los estoicos s.v., N. Abbagnano (editado), Storia della filosofia, vol. I, Turín 1993, p.216, en el que se observa cómo "para los estoicos la ética es fundamentalmente una ética del deber y la noción de deber, como conformidad o conveniencia de la acción humana al orden racional, se convierte por primera vez, para los estoicos, la noción fundamental de ética "; siempre sobre el tema s.v; según lo expuesto BETTI, E., Dovere giuridico, voce, en "Enciclopedia del diritto", XIV, Milán 1965, pp. 53-58, en el que se observa cómo "ya que el hombre no vive aislado, sino en comunión con sus similares, se cree con razón que él, en la vida de las relaciones, se comporta de manera que les sea útil: cumpliendo así su deber, produce su propia felicidad y la de los demás, en la que se identifica la justicia social “.

14 Diogene Laerzio, Vita dei filosofi, trad. it., Laterza, Roma-Bari 1976, VII, pp. 107-109.

15 Abbagnano, N., (a cura), Dovere, cit., p. 266. 
Deber, para Kant es sólo la acción realizada en vista de la ley y en cumplimiento de la ley y es, por tanto, la única acción racional auténtica, es decir, determinada exclusivamente por la forma universal de la razón. En este sentido, una acción realizada por deber tiene su valor moral, según Kant, "no en el propósito que debe alcanzar, sino en la máxima que la determina". Por tanto, el deber es "la necesidad de realizar una acción únicamente para el cumplimiento de la ley"16, donde la palabra respeto significa una actitud que es independiente de todas las inclinaciones naturales. De lo que se ha informado hasta ahora, es bastante evidente que la noción de deber sea ab origine un concepto específico de moralidad y designa, - como enfatiza Kelsen- "la norma moral en su relación con el individuo a quien se prescribe o prohíbe. por la norma una conducta determinada"17.

Una vez aclarada - aunque sea brevemente- la noción de deber podemos introducir la deontología, que como hemos visto anteriormente tiene un deber inherente.

\section{ORIGEN Y EVOLUCIÓN DE LA DEONTOLOGÍA}

Jeremy Bentham - exponente de la Ilustración y post-Ilustración del siglo XIX y fundador de la escuela filosófica inglesa del utilitarismo - en 1834 fue el responsable del uso, por primera vez, del neologismo deontología, a la que en su obra Deontología o Ciencia para La moralidad ${ }^{18}$ la definió como la disciplina de las acciones

16 Kant, I., Critica della ragion pratica, trad. it., Editrice La Scuola, Brescia 1962, p.82, el concepto de deber exige, prosigue Kant, "en la acción, objetivamente, acuerdo con la ley y, en su máxima expresión, subjetivamente, respeto a la ley, como única vía para determinar la voluntad a través de la ley misma. En esto se basa la diferencia entre la conciencia de haber actuado de acuerdo con el deber, y la de haber actuado por deber, es decir, por respeto a la ley: la primera (la legalidad) es posible incluso cuando las inclinaciones puras y simples. han sido la razón determinante de la voluntad, mientras que la segunda (la moral), que es el valor moral, debe hacerse constar en esto, que la acción se realiza por deber, es decir, únicamente en vista de la ley “.

17 Kelsen, H., Teoria generale del diritto e dello stato, (1945) trad. it., Etas, Milano 2000, p. 58.

18 Cfr., Bentham,J., Deontologia (1834), trad. it., La Nuova Italia, Florencia 2000, el trabajo se divide en dos partes: la primera es la "deontología teórica", que expone las nociones de bienestar y malestar, refuta la noción de Bien Supremo, explica la relación entre placer y dolor y el bien y el mal, denuncia el papel de causa de inmoralidad de la religión, define la noción de virtud en general y las virtudes individuales en particular, reduciéndolas a la prudencia, la probidad, la beneficencia; la segunda es la "deontología práctica", que explica cuál es la función del moralista práctico, ilustra los placeres de la benevolencia efectiva y distingue entre la prudencia hacia uno mismo y la prudencia hacia los demás, profundizando en los detalles 
humanas a las que el derecho positivo deja el campo libre. El conocimiento de lo que es correcto y de lo que es apropiado. Una doctrina utilitarista de los deberes, como la definió el propio Bentham, especificando nuevamente como "deontología" entendida en el sentido más amplio, se entiende aquel sector del arte y la ciencia que tiene como objeto hacer en cada ocasión lo que es correcto y conveniente hacer"19. Tal definición se refiere a la teoría de una ciencia de lo conveniente o lo útil, es decir, el cálculo de las consecuencias determinadas por una acción, como para poder elegir la que conlleva el mayor bienestar para un mayor número personas.

En otras palabras, el hombre en todas sus acciones siempre tiene como objetivo principal la búsqueda y la consecución de su propio placer personal ${ }^{20}$. En este sentido, la tarea de la deontología, para Bentham, consiste principalmente "en la distribución de las obligaciones: en marcar en el campo de acción los lugares en los que se puede considerar convenientemente que surja una obligación; y, en caso de conflicto entre obligaciones derivadas de distintas fuentes, en establecer cuál debe obtener la preferencia y cuál debe renunciar a ella"21, es decir, en enseñar "cómo el hombre deba dirigir sus emociones de manera que las mismas se subordinen al propio bienestar"22.

La deontología, por tanto, en la perspectiva utilitaria de Bentham es una ciencia del bien y de la oportunidad para el único logro del bienestar del hombre. En realidad, la deontología aparece en términos benthamitas como una especie de "microética individual y privada" 23 . Pero quedarse anclado a tal definición es bastante engañoso, ya que de hecho otra elaboración, como veremos a continuación, ha inspirado la conceptualización de los códigos profesionales. En realidad, la inspiración para la deontología actual es la

de la etiqueta; la doctrina en la que se basa la deontología de Bentham es el principio consecuencialista que establece qué acciones son justas y cuáles injustas, según la cantidad de bien producido como consecuencia de nuestras acciones; al respecto, GUERrinI, M., Il web e la deontologia professionale. Condividere le finalità tra bibliotecario e utente, in FogLIENI, O., (a cura), La biblioteca condivisa: strategie di rete e nuovi modelli di cooperazione, Editrice Bibliografica, Milano 2004, p. 229, observa cómo "el uso actual de la palabra ahora tiene poco que ver con el contenido de la ética benthamiana en la que el concepto de deber asume un papel marginal".

19 Bentham, J., op.cit., p. 16.

20 Cfr., Lodovici, G.S., L'utilità del bene: Jeremy Bentham, l'utilitarismo e il consequenzialismo, Vita\&Pensiero, Milano 2004, p. 7.

21 BenTHAM, J., op. cit., p. 57.

22 Bentham, J., op. cit., p. 16.

23 Herranz, G., Deontologia (parte etica), voce in "Enciclopedia di Bioetica e Scienza Giuridica", IV, ESI, Napoli 2011, pp. 156. 
matriz filosófica kantiana ${ }^{24}$. Los famosos "imperativos categóricos" sirven a Kant para construir un conjunto de principios universales mediante los cuales poder juzgar las acciones humanas. De hecho, "la centralidad del deber, la obligación moral y la norma" representan el entramado del pensamiento kantiano, tanto es que "es precisamente el carácter deontológico de la ética lo que se absolutiza y no deja lugar a otros criterios u otros puntos de vista desde donde poder ver la acción $»^{25}$.

El carácter absoluto del deber no deja lugar a la acción a excepciones de ningún tipo, y es precisamente este carácter absoluto, que a su vez sustenta la obligación, el que constituye el criterio distintivo de las diversas teorías deontológicas. Esto hace posible, sin sombra de negación, argumentar que la teoría kantiana "es una forma pura y radical de deontología" ${ }^{26}$. Totalidad y universalidad, de hecho, constituyen las características fundamentales de la obligación moral en términos kantianos.

Kant, en realidad, aspiraba a crear, mediante una formulación filosófica de la deontología, un sistema ético que no dependiera de la experiencia subjetiva, sino de una lógica irrefutable. Lógica, a la que Kant asigna la tarea de establecer la corrección o no de una acción. En este sentido, la deontología representa ese conjunto de principios y normas que orientan la conducta de los miembros pertenecientes a una determinada categoría profesional. El recurso cada vez más frecuente a la aprobación de códigos atestigua la necesidad de que las normas deontológicas ya no se limiten únicamente a las reglas sociales y morales, sino que estas últimas influyan en el "proceso de investigación, selección e interpretación de las normas a aplicar en casos concretos" 27 .

Dicho esto, la función cada vez más significativa que asume la deontología requiere que se preste atención y se examine cuidadosamente la naturaleza de las reglas deontológicas. De hecho - como se representa más adelante - el debate teórico sobre la naturaleza de estas normas se puede resumir distinguiendo cinco posiciones

24 Cfr., Fonnesu, L., Dovere, La Nuova Italia, Firenze 1998, p. 91, quien sostiene que «la teoría deontológica por excelencia es la teoría ética de Kant: ésta representa al mismo tiempo tanto la forma radical como la estructura fundamental de una teoría deontológica ».

25 FonNESU, L., op. cit., p.92.

26 IBIDEM

27 Cfr., Pizzorusso, A., Il "codice etico" dei magistrati italiani, in Aschettino,L. - Bifulco,D. -Epineuse,H. - Sabato, R. (a cura), Deontologia giudiziaria. Il codice etico alla prova dei primi dieci anni, ESI, Napoli 2006, p. 60. 
diferentes que vendrán aquí, ampliamente analizadas. La primera posición cree que las reglas deontológicas deban ser consideradas como "preceptos extrajurídicos", es decir "reglas dentro de las categorías", por lo tanto, como tales, no pueden elevarse a las normas del ordenamiento general. ${ }^{28}$

Una segunda posición considera que tales normas, en cuanto expresión de la autodisciplina profesional, adquieran eficacia jurídica en el ámbito del ordanamiento estatal cada vez que intervienen en asuntos regidos por la normativa estatal mediante la elaboración de principios y cláusulas generales ${ }^{29}$; una tercera posición es aquella que, aceptando la enseñanza de doctrinas que reconocen la pluralidad de los ordenamientos jurídicos, sostiene que las reglas deontológicas constituyen la expresión de un sistema particular integrado dentro del ordenamiento estatal ${ }^{30}$; y nuevamente, la posición contraria que, recordando la elaboración conceptual en la base del fenómeno del policentrismo normativo, enmarca la codificación deontológica en clave de autopoiesis de normas plenamente jurídicas capaces de ingresar en el ordenamiento general ${ }^{31}$; y finalmente, una disposición adicional contempla el carácter consuetudinario de las normas deontológicas, atribuyendo a los códigos deontológicos funciones de recogida de usos. ${ }^{32}$

De este acercamiento inicial se evidencia, claramente, cuál sea el interés que hoy reviste toda discusión sobre la deontología y esto se debe a que existe una necesidad creciente, por un lado, del respeto por parte del profesional de un modus agendi orientado deontológicamente, de proteger no solo y / o no tanto la categoría profesional, sino al usuario de la actividad regulada; mientras que, por otro lado, se debe a la intensificación de intervenciones legislativas que, de diversas formas, están interesados en la disciplina deontológica. ${ }^{33}$

28 Cfr., Sandulli, A.M., Regole di deontologia professionale e sindacato della Corte di cassazione, in "Giustizia civile”, I, 1961, p.616.

29 Cfr., Bellelli, A., Codice di deontologia medica e tutela del paziente in "Riv. Dir. Civ", II, 1995, p. 581.

30 Cfr., Comporti, G.D., La deontologia medica nella prospettiva della pluralità degli ordinamenti giuridici, in "Riv.it. med. leg.", 2002, p. 859.

31 Cfr., AlPa, G., Le "fonti" del diritto civile: policentrismo normativo e controllo sociale, in www.consiglionazionaleforense.it

32 Cfr., D'Angelo, A., Diritto deontologico e giurisdizione degli ordinamenti professionali sulla responsabilità disciplinare dell'avvocato, commento a Sent. 4 ottobre 2000., n. 1053, Cass. Civ. sez. un., in "Danno e responsabilità", 2001, p. 613.

33 LAONIGRO, P., Le norme deontologiche tra teoria e prassi giurisprudenziale: notazioni sul codice deontologico medico, in "Amministrazione in Cammino", 2010, p. 3. 
Por otro lado, la referencia constante, de parte del legislador, a la creación de códigos deontológicos de conducta y autodisciplina, no hace otro que confirmar la existencia de un pluralismo normativo articulado y policéntrico. ${ }^{34}$ De esta forma, los códigos tienen un reconocimiento formal por parte del ordenamiento estatal. ${ }^{35}$ Este último aspecto, de hecho, enfatiza la importancia real de los códigos deontológicos sobre los cuales es oportuno prestar una mayor atención. ${ }^{36}$

\section{LA NATURALEZA DEL 'DEBER' DE LOS CÓDIGOS DEONTOLÓGICOS Y LA ÉTICA PROFESIONAL}

La definición de código deontológico viene dada por la unión de dos términos, cuyos orígenes etimológicos derivan, el primero - código- es el nombre que los Romanos daban a las tablillas de madera recubiertas de cera sobre las que escribían y que estaban encuadernadas en forma de libro compuesto de varias hojas cosidas juntas. $^{37}$

Conjunto de reglas que regulan, de manera orgánica, un sector de la vida asociada o el conjunto de diversas manifestaciones del mismo; mientras que deontológico, como lo hemos señalado anteriormente, es la "ciencia que trata de los deberes a realizar". El código deontológico representa, por así decirlo, un hito, ya que revela los derechos y deberes que tienen los profesionales, cuya

34 Così, Perfetti, U., Codice deontologico forense e natura delle norme deontologiche, in AlPa, G.-Zatti,P., (a cura), Codici deontologici e autonomia privata, Giuffrè, Milano 2006, p. 946.

35 In merito P. BILANCIA, Attività normativa delle Autorità indipendenti e sistema delle fonti, Giuffrè, Milano 1999, p. 161.

36 Cfr., Benatti, F., I codici deontologici come tutela essenziale del mercato, in "Rassegna Forense", n. 2, 2015, pp. 373-390.

37 Cfr., Mirabella, P., L'uomo e i suoi diritti, Effatà Editrice, Torino 2009, p. 139, quien subraya que “el término 'código' se refiere a aquellas recopilaciones orgánicas, generalmente escritas, de reglas de comportamiento a las que un grupo social confía la protección de su sistema ético general; mientras que el uso adjetivo del término deontología especifica que las reglas recogidas en ese código definido como "deontológico" se refieren al conjunto de valores, principios, reglas y hábitos que un determinado grupo profesional establece y se compromete a observar en el ejercicio de su profesión "; nuevamente a este respecto F. Benatti, op.cit., p. 375, en el que el A., destaca cómo "históricamente los códigos deontológicos tienen sus raíces en los gremios medievales y sus estatutos. Sirvieron para regular el mercado, para regular la conducta de sus afiliados y brindaron la asistencia necesaria, también en referencia al perfil formativo de los jóvenes, pero sobre todo fijaron estándares de calidad, prohibiendo conductas graves y nocivas para el consumidor. Esto surge claramente al examinar las reglas que las propias corporaciones se dieron a sí mismas ». 
conducta "se inspira en valores precisos que se traducen en principios operativos". ${ }^{38}$

Por tanto, tiene la función de regular la actividad de los profesionales relacionados con ella y basa su normativa en algunos valores básicos, de los que derivan los principios éticos que, además de inspirar las normas, vienen consultados en casos de dificultad de interpretación de las mismas. Los valores básicos surgen de una visión filosófica y existencial del hombre y son universalmente válidos, trascendiendo tanto a las normas culturales como al desarrollo de la realización individual.

La ética que se deriva de ellos puede definirse como la búsqueda de uno o más criterios que permitan al individuo gestionar adecuadamente su libertad en el respeto a los demás. También exige, además, una base racional, como tal no emotiva, en la actitud asumida, que no puede reducirse a desiquilibrios de solidaridad o amorosos de tipo irracional. En este sentido, establece un marco de referencia, de cánones y límites dentro de los cuales la libertad humana puede extenderse y expresarse. Es importante comprender cómo ética y deontología, de hecho, no son la misma cosa, sino dos formas diferentes de abordar un tema. ${ }^{39}$ Ambas se preocupan de aquello que es mejor para toda la comunidad. En realidad, se complementan y se contemplan, ya que la "deontología tiene como objetivo la búsqueda de nuevas perspectivas, proponiendo una ética comunitaria

38 GHISALBERTI, R., Il Codice deontologico nella realtà operativa: spunti da un lavoro di verifica con i professionisti, in AMADEI,T.-TAMBURINI,A., (a cura), La leva di Archimede, Franco Angeli, Milano 2002, p. 105; sono, - también comenta F. Benatti, op.cit., p. 378 - «una forma de autorregulación que permite anticipar y responder a las necesidades de la sociedad, equilibrando los intereses de la profesión con los de los actores externos. Se trata del reconocimiento de otras formas de producción del derecho también para llenar los vacíos en la legislación y contribuir al progreso de las normas en presencia de una realidad en constante evolución. En particular, la actualización continua de los códigos deontológicos permite una mejor y más flexible adaptación a los cambios. Son la afirmación de los valores y principios de una categoría, pero están fuertemente influenciados por el contexto social, legal, económico cuyas necesidades también reflejan ".

39 En cuanto a la distinción entre ética y deontología, remito a E. GUISÁN, Ètica y deontologìa, in “Ètica, deontologìa y bibliotecas", n. 96, 1999, p. 44, in l'A., remarca como «la ética significa preocuparse por uno mismo y por todos los demás. Engrandecerse, engrandecer a los otros. Expulsar los malos espíritus de la envidia y la discordia de la casa del mundo. La deontología, que es el estudio de los deberes de los seres humanos en cuanto miembros de una profesión, no puede tener otra misión que ayudar a procurar la felicidad de los usuarios de un servicio sin menoscabo de la igual felicidad de quienes se lo proporcionan». 
que sea válida para todas las personas que desarrollan una actividad laboral". ${ }^{40}$

La deontología tiene como propósito la de "conciliar" la forma, las modalidades generales de una profesión determinada, las situaciones concretas de cada miembro perteneciente a un orden profesional, adaptando así los presupuestos de la ética individual a toda una colectividad que es específicamente la profesional.

Una ética colectiva en la que haya principios bien definidos, que se remontan a establecer valores que sirven como estándares fundamentales para la actividad de los profesionales, de los deberes profesionales. Toda actividad laboral debe perseguir un objetivo ético que es, en última instancia, el cumplimiento de un deber bien definido en cada profesión. De esta forma, "el deber se convierte en un deber por el deber, asumido profesionalmente, es decir, dirigido a través del trabajo a satisfacer las necesidades de los demás". ${ }^{41}$ La ética deontológica o código deontológico representan las reglas del "deber profesional"; protegen por un lado al profesional individual que sabe qué criterios debe respetar para poder ejercer y mantenerse dentro de la categoría a la que pertenece, y por otro lado al cliente que haciendo uso de ese servicio profesional, está garantizado del servicio prestado por el hecho de que el profesional debe cumplir con las normas deontológicas si quiere seguir desarrollando su actividad.

De este modo, la deontología de las distintas profesiones no puede basarse de manera extraña en acuerdos con los intereses de un determinado grupo profesional, sino que debe incluir el bienestar común, tanto de los profesionales como de los usuarios". La profesión médica ha sido la primera en nuestro país que reconoció el concepto de deontología, y esto probablemente fue posible debido al cambio en la cultura médica de la relación médico-paciente, por lo que para el médico, referirse al principio del deber correspondía al nuevo tipo de relación establecida, ya no paternalista, sino basada en los derechos del paciente y, por tanto, en los deberes de los médicos.

La deontología médica, de hecho, es el conjunto de reglas que el médico está obligado a observar al tratar con pacientes, con colegas o con la sociedad. El primer código deontológico nos remite entre el

40 Garcìa FernándeZ, A., Ètica y deontologìa, in “Ética y Bibliotecas”, n.159, 2007, p.67, por lo que continúa l'A., - «la Deontología necesita de la tensión individual entre lo que soy y lo que debería ser que se da en la Ética para proponer normas de acuerdo con la actividad laboral conjunta a la que quiere responder con un mejor funcionamiento de la profesión».

41 GARCÌA FERNÁNDEZ, A., Ètica y deontologìa, cit., p.72. 
460 y el 377 a.C. a Hipócrates uno de los más grandes médicos de la antigüedad. El Juramento Hipocrático, con las normas consuetudinarias en las que se inspira y las reglas que contiene, puede considerarse con razón como el más citado y extendido código de deontología ante litteram..$^{42}$ Está estructurado según una lógica muy precisa y representa toda una serie de determinaciones más que la aceptación pasiva de actividades obligadas. ${ }^{43}$ Hipócrates introduce por primera vez el concepto de secreto profesional, la condena por el asesinato de la parte que consiente.

De hecho, en la época de Hipócrates el juramento no tenía el valor de un verdadero código ético, sino que asumía un significado meramente práctico. Muchos de los contenidos del Juramento Hipocrático han sido recogidos en códigos modernos de deontología médica, aunque sea diversa la forma en que el profesional aborda los temas encaminados a lograr una conducta profesional acorde con las necesidades del paciente. Por tanto, se ha pasado de asumir compromisos a realizar actividades fuera de nuestro deber. De hecho, el primer código con intenciones deontológicas es el babilónico, conocido como el Código de Hammurabi que data de 1792 a. C.

Este código sancionaba algunas reglas relativas al arte médico con referencia específica a la cirugía. Lo interesante de subrayar es cómo, incluso entonces, preveía las sanciones para los médicos que no prestaran diligentemente su arte. El código deontológico, por tanto, es la exposición, en forma de artículos, de los contenidos de la deontología profesional. Entre las muchas funciones del código deontológico también se encuentra la de promover y mantener estándares éticos de conducta profesional. De hecho, el código deontológico, aunque se extiende al ámbito jurídico, prefiere el aspecto ético. Podríamos definirlo como un puente entre dos ámbitos diferentes. De profesión y de conducta profesional, por extraño que parezca, Santo Tomás se ha ocupado ampliamente, de hecho podría considerarse precisamente a Tomás de Aquino como el creador de la ética profesional ${ }^{44}$, ya que fue el primero en analizar las diferencias generales de la vida y las diferentes actividades humanas.

42 Calcagni, C. - Cecchi, R., Deontologia medica, Società Editrice Universo, Roma 2008, p.39.

43 RodrÍGuez, D., Le fonti deontologiche delle professioni sanitarie, in Rodotà, S.-Tallachini,M., (a cura), Trattato di biodiritto, Giuffrè, Milano 2011, p. 827.

44 En este sentido, para más información, remito a Forment GIRALT,E., Fundamentacion de la deontologiain "Annales del Semonario de Metafisica", n.1, 1992, p. 710 . 
De hecho, en la Summa Contra Gentiles, Santo Tomás refiere que el hombre necesita muchas cosas para poder vivir, "que no puede obtener por sí mismo, precisamente las cosas diferentes son hechas por distintos hombres, por ejemplo, uno es agricultor, otros pastores, otros constructores, y así en otros casos,... y como la vida de los hombres no requiere solo cosas corporales, sino principalmente cosas espirituales, es necesario que algunos se dediquen a las cosas espirituales en beneficio de los demás, quedando exentos de la ciudadanía temporal» ${ }^{45}$.

La profesión, en efecto - siguiendo el razonamiento de Santo Tomás- es una actividad personal, realizada por vocación propia, al servicio de los demás. En esta definición están contenidos los tres elementos esenciales de la profesión tomados del texto de Santo Tomás. El primero define la profesión como una actividad propia de quien la pone en práctica; el segundo elemento imprescindible es la vocación, y el tercero y último elemento hace referencia a la finalidad social de cada profesión. A la finalidad social de la profesión Santo Tomás atribuye un propósito fundamental, ya que si no pones tus conocimientos y esfuerzos al servicio de los demás, y solo piensas en el aspecto remunerativo del trabajo, no eres realmente un profesional. ${ }^{46}$ Dicho esto, es interesante subrayar cómo el discurso realizado hasta ahora, a través de las reflexiones de Santo Tomás, hoy más que nunca, es de gran relevancia, considerado el gran interés, demostrado por muchos, por la ética profesional. Un interés, probablemente, debido a las profundas innovaciones implementadas por la tecnología disruptiva, tanto en el campo del conocimiento como en el de la comunicación, o quizás por la crisis desenfrenada en todos los sectores. Si consideramos que toda profesión es ejercida por hombres y dirigida a otros hombres, por lo que tiene repercusiones directas o indirectas sobre el hombre, es fácil comprender cómo tenga necesariamente implicaciones de carácter ético.

Evidentemente, hay profesiones que tienen mayores implicaciones desde el punto de vista ético, considerando que el espacio de decisión y discreción es más amplio, pero, además, mayores son las responsabilidades que recaen sobre estos profesionales, como por ejemplo los médicos. A menudo se tiende a reconducir la deontología, o los códigos deontológicos, hasta la ética, pero no es propio así. La relación que une ética y deontología debe entenderse como la relación entre género y especie, en la que "la primera constituye ese

45 Tommaso D'Aouino, Summa contra Gentiles, III, 134 c.

46 Cfr., Tommaso D’Aouino, Summa Theologiae, II, q. 183 a. 3. 
universal necesario dentro del cual se destacan, se definen y caracterizan las áreas individuales de la segunda, es decir, los horizontes de reglas, cánones de normas o sólo las pautas de las que se informa a las colectividades, grupos, clases y corporaciones humanas ${ }^{47}$. Esto significa que no es concebible de ninguna manera una deontología al margen de la ética, de una ética entendida como una disciplina atenta a los valores de una comunidad. Todo esto implica la comprensión necesaria de la naturaleza de las normas deontológicas.

\section{REGLAS DEONTOLÓGICAS: FUNCIONES Y CALIFICACIÓN JURÍDICA}

La relación entre ética y moral, así como la relación entre derecho y moral, ha sido a lo largo del tiempo objeto de intensas discusiones doctrinales y jurisprudenciales. En un contexto social permeado por la consecución de beneficios, la obtención de rentas, en una palabra de la economía, la ética deberá configurarse como una especie de 'navegante' de la acción humana (empresarial, profesional) para discernir lo justo de lo 'injusto", para orientarse mejor en la búsqueda de objetivos y en la elección de los medios para alcanzarlos.

Las dimensiones en las que se mueve esta acción, son la consecución del objetivo y la responsabilidad individual y colectiva, que se fundamentan esencialmente en la ética y la moral. Sin profundizar más en la definición de ética - ya investigada anteriormente - podemos, inicialmente, asumirla como la que actúa de acuerdo con un comportamiento correcto, es decir, de buena fe y confianza mutuas, de manera que constituya un recurso primordial para la consecución de los objetivos empresariales y profesionales, actuando como un trasfondo necesario para las elecciones a realizar. En este contexto, se crean así nuevos y más eficientes "códigos de conducta" sea éticos que de buenas prácticas, que adquieren vigencia en la sociedad y en el trabajo tout court.

Entre los códigos de conducta y a efectos de su calificación jurídica, se examinarán los de deontología profesional, con especial referencia al forense y médico. A través de la deontología - como se dijo anteriormente- las profesiones exhiben sus credenciales ante la sociedad en la que operan, adoptando formas de autodisciplina que van desde un simple juramento hasta el código real.

47 Calcagni, C.- CECchi, R., Deontologia medica, cit., pp. 13-14. 
Es un conjunto de reglas que deben informar la conducta del profesional y calificar al grupo organizado al que pertenece, en otros términos, una ética acorde al rol, que esencialmente cumple dos funciones: desde el punto de vista externo, representa un indicador de los deberes y privilegios particulares que a lo largo del tiempo se le han atribuido social e institucionalmente a su actividad; en el plano interno, consiste en un conjunto de directrices encaminadas a resolver los problemas prácticos y los dilemas éticos inherentes al ejercicio de la profesión. ${ }^{48}$

La deontología profesional tiende al "proceso de construcción de una imagen, más o menos correspondiente a la realidad, mediante la cual toda profesión trata de hacer socialmente aceptable el goce de ciertos privilegios, auto-obligándose a cumplir determinados deberes sociales y a superar el egoísmo de los profesionales individuales" 49 . Esta, fundamentalmente, tiene la tarea de coordinar con la normalidad social el estado de excepción representado de la ética según el rol profesional y de frenar, de manera autodisciplinar, la posibilidad de excesos en el ejercicio de su propio poder técnico por parte de los profesionales.

Este concepto, es decir, de ética fuertemente ligado al rol, encuentra su lugar en el Código Deontológico de la Abogacía Europea, el cual establece que "en una sociedad fundada en el respeto a la justicia, el abogado juega un papel especial. Su tarea no se limita al fiel cumplimiento de un mandato en el ámbito de la ley. El abogado debe garantizar el respeto del Estado de Derecho y los intereses de aquellos cuyos derechos y libertades debe defender; el abogado tiene el deber no solo de defender el caso, sino también de ser el consejero de su cliente. El respeto de la función profesional del abogado es una condición esencial del Estado de Derecho y de una sociedad democrática ". .50

48 Cfr., Caravita,L.,Dall'etica alla deontologia medica, in Helzel, P.B., (a cura), Quale bioetica per il terzo millennio?, Laruffa Editore, Reggio Calabria 2021, pp. 181-206.

49 Cosi, G., Etica secondo il ruolo e deontologia: il problema dell'identità professionale, in "Rivista della Scuola superiore dell'economia e delle finanze", n. 5, 2007, pp.19 e ss.

50 Código Deontológico de los Abogados Europeos del CCBE, artículo 1.1. El Código Deontológico de los Abogados Europeos fue adoptado originalmente por la Sesión Plenaria de CCBE el 28 de octubre de 1988 y posteriormente fue modificado por las Sesiones Plenarias de CCBE el 28 de noviembre de 1998, el 6 de diciembre de 2002 y el 19 de mayo de 2006. El Código también incorpora la modificaciones introducidas en el Estatuto de CCBE y aprobadas por el Pleno Extraordinario de 20 de agosto de 2007. 
La práctica profesional, por tanto, implica el deber de atenerse a las reglas de conducta, algunas de las cuales no están sancionadas por la ley, otras están identificadas por la deontología profesional. En este contexto, las reglas deontológicas tienen una función propia y específica y se sitúan, dentro de los ordenamientos jurídicos, en el centro del constante diálogo jurisprudencial entre su naturaleza jurídica o extrajurídica, desbordando así su ámbito de vigencia en el conocido binomio entre la ley y la ética. Las normas deontológicas adquieren así especial relevancia bajo un doble perfil, el de su función y el de su calificación jurídica. La función de las reglas deontológicas, respecto a las que ya hemos argumentado extensamente, tiene por tanto el objetivo de garantizar la actuación de los profesionales basada en el buen funcionamiento de la empresa respecto al papel que desempeñan dentro de ella. Principios fundamentales, estos últimos que, "aunque con variaciones mínimas en los distintos ordenamientos jurídicos, son comunes a todos los abogados europeos". Tales principios fundamentales son la base de varios códigos nacionales e internacionales que rigen la deontología forense. Los abogados europeos están sujetos a tales principios, esenciales para la buena administración de la justicia, el acceso a la justicia y el derecho a un juicio justo, tal como lo prescribe el Convenio Europeo de Derechos Humanos". ${ }^{11}$ En lo que respecta a la deontología profesional, se trata de normas de conducta que se basan en el fundamento del deber, impuesto a los abogados (por ejemplo, el artículo 12 de la ley forense italiana) de "desempeñar su ministerio con dignidad y decoro, como corresponde a la altura de la función que están llamados a ejercer en la administración de la justicia”. El mismo artículo, al disponer la fórmula del juramento que debe prestarse para el ejercicio de la profesión, hace referencia al cumplimiento de los deberes profesionales "con lealtad, honradez y diligencia". El cumplimiento de estos deberes está garantizado por las asociaciones profesionales $\mathrm{y}$, en particular, por el poder disciplinario. ${ }^{52}$

Por tanto, hablar de deontología significa abordar — como se ha argumentado anteriormente- un tema relacionado con los deberes, más precisamente se trata de discutir la ciencia del deber, un conjunto de principios y normas que orientan la conducta de los integrantes de una categoría profesional ${ }^{53}$, hacia un modelo estándar

51 Carta de principios fundamentales del Abogado Europeo Adoptada en Sesión Plenaria por el Council of Bars and Law Societies of Europe (CCBE) del 25.11.2006.

52 Pubblico, v. in “Digesto”, vol. X, n. 92, UTET, Torino 2007.

53 LEGA, C., Deontologia forense, cit., p. 38. 
que no solo es repetitivo de lo que la ley ya impone, sino más allá y más estricto.

\section{DEONTOLOGÍA FORENSE}

Llegados a este punto, es más útil que nunca, a los efectos del trabajo, analizar cuál es la naturaleza de las normas deontológicas, así como ya en 1977 la Declaración de Perugia sobre los principios de la conducta profesional ${ }^{54}$, había indicado (artículo 1) al afirmar que "las reglas de conducta profesional no tienen por objeto simplemente definir obligaciones, cuya violación puede dar lugar a una sanción disciplinaria". Una sanción disciplinaria se impone solo como último recurso. De hecho, puede tomarse como una indicación de que la autodisciplina de los miembros de la profesión no ha tenido éxito. Las reglas de conducta profesional están diseñadas, a través de su aceptación voluntaria por los abogados interesados, para asegurar el adecuado desempeño por parte de los abogados de una función que es reconocida como esencial en todas las sociedades civiles.

Las normas particulares de cada Colegio de Abogados están vinculadas a sus propias tradiciones y se adaptan a la organización y al ámbito de actividad de la profesión en el país de que se trate, a sus procedimientos judiciales y administrativos y a su legislación nacional. No es posible ni deseable que se extrapolen de su contexto ni que se intente dar una aplicación general a reglas que son intrínsecamente incapaces de tal aplicación. En la búsqueda de una base común para un código de conducta profesional para la Comunidad, se debe partir de los principios comunes que están en el origen de las normas específicas de cada país miembro".

Sin embargo, sobre la calificación de la naturaleza de las reglas deontológicas no existe una opinión compartida, sobre todo por parte de la jurisprudencia, que a lo largo de las distintas sentencias ha cambiado de orientación. Entre las diferentes opiniones a prima facie contradictorias..$^{55}$

Según una primera opinión que se remonta a los años sesenta y en parte seguida hasta ahora, se cree que las normas deontológicas no son jurídicas; Se afirma, en efecto, que si el derecho reserva a los poderes de autonomía de la clase y de sus órganos la creación,

\footnotetext{
54 Adottata dal Consiglio degli Ordini Forensi Europei (CCBE) nel 1977.

55 Cfr., Perfetti, U., Ordinamento e Deontologia Forensi, Cedam, Padova 2011.
} 
identificación y aplicación de las reglas deontológicas, no los exime a las normas del ordenamiento general y no los asimila a éstos, ya que las fuentes extrajurídicas no se transforman (al menos por regla general) en fuentes del ordenamiento jurídico en general. ${ }^{56}$

A partir de este supuesto la razón por la cual la Autoridad Judicial del Estado no puede interferir en la identificación de las reglas deontológicas; no tanto porque el sector esté marcado por la discreción de la jurisdicción profesional, sino porque la codificación deontológica es expresión del mérito de una actividad orientada a investigar y aplicar normas extrajurídicas, actividad excluida, como tal, de la función de nomofilaquía de los jueces de legitimidad. ${ }^{57}$

Este aparato conceptual y la relativa solución han sido compartidos durante mucho tiempo por los Tribunales de legitimidad (por ejemplo, el Tribunal de Casación italiano, justificando su indiscutible identificación y aplicación - en relación a las objeciones - de las reglas deontológicas profesionales desarrolladas por el Consejo $\mathrm{Na}$ cional Forense, ha argumentado en varias ocasiones que esto es consecuencia de ser normas, ahora definidas como extrajurídicas (ex plurimis Cass. Sect. unite n. 8239 de 23 de julio de 1993), ahora internas, tales, en todo caso para no llegar nunca a rango de normas del ordenamiento general y constituir expresión de verdadera actividad normativa (Cass. Sect. unite n. 401 de 17 de enero de 1991).58 Una teoría al estilo kelseniano, donde todo aquello que no proviene de la Autoridad del Estado y que no es posible volver al ámbito del derecho en sentido estricto no se incluye dentro del ordenamiento jurídico, confinando el "deber" ético a la reglas de carácter deontológico. Recordando que no existen mala in sé, sino mala prohibita, es decir, no hay conductas que se definan como ilegales si no hay una regla que las califique como tales. ${ }^{59}$ Esta es una primera teoría que concluye afirmando que las normas deontológicas no son jurídicas.

Según otra opinión, se puede vislumbrar el carácter consuetudinario de las normas deontológicas, considerando, por tanto, el código deontológico como un conjunto de usos. En esta dirección podrían interpretarse algunas (raras) alusiones de la jurisprudencia cuando se refiere a las normas deontológicas como “... a los principios establecidos por el código deontológico sobre la communis

56 Cfr., SAndulli, A.M. Regole di deontologia professionale e sindacato della Corte di cassazione, in "Giustizia civile", n. 1, 1961, p. 619.

57 Cfr., Sandulli, A.M., op. cit. p. 616.

58 Cfr., Perfetti, U., op. cit., p.

59 Cfr., Calabrò,G.P. - Helzel, P.B., Il sistema dei diritti e dei doveri, Giappichelli, Torino 2007. 
opinio de los miembros pertenencientes a la categoría" (Cass. N. $6213 \backslash 2005)$.

Esta orientación de la jurisprudencia sobre la naturaleza jurídica de las normas deontológicas, que optaba por la conclusión, según la cual, estas constituyen normas extra jurídicas o normas internas a la categoría y no, en cambio, normas del ordenamiento jurídico en general, mientras que por el lado de su relevancia se cree que pueden complementar las reglas de la ética profesional..$^{60}$ Por tanto, ante el revirement jurisprudencial en clave evolutiva, surge la orientación tradicional del propio Colegio Supremo italiano, que en cambio afirmaba que las reglas de origen ético constituyen una expresión de preceptos extrajurídicos, o reglas internas de la misma categoría. y no ya de actividad reguladora (Cassazione Sezioni Unite $1148 \backslash 1996$ ).

En cuanto a la definición de la norma deontológica y su ubicación en el marco sistemático de las fuentes, un punto de inflexión lo dio la sentencia de las Secciones Unidas de la Corte de Casación con sentencia núm. $26810 \backslash 2007$. Con esta sentencia, el Tribunal estableció el principio según el cual las disposiciones que en el código deontológico representan fuentes normativas complementarias del mismo precepto legislativo, que confieren al Consejo Nacional de Abogados (C.N.F.) la facultad de dictar normas con función de jurisdicción especial, que forman parte del sistema general del Estado y, como tales, pueden estar sujetas a interpretación por parte del Tribunal de Casación. ${ }^{61}$ De hecho, según la opinión que prevalece actualmente en la doctrina y en la jurisprudencia, la norma deontológica asume el carácter propio de norma jurídica. El iter lógico que atraviesa la doctrina para predicar la naturaleza de la norma jurídica de la deontológica realza el hecho de que es la propia ley la que atribuye a los órganos autónomos la facultad de emitir mandatos concretos y singulares, para lo cual la producción de la regla y la coerción encuentran su fundamento en el derecho positivo. ${ }^{62} \mathrm{Se}$ trata, en efecto, como también se ha señalado en la doctrina, de una condición necesaria para la preservación misma de la dignidad y el decoro. La dato positivo que se acaba de mencionar parece ser preciso y claro, en la parte en la que establece que los abogados están llamados a cumplir su ministerio con dignidad y decoro, en la medida en que sea conveniente en relación con la altura de la función

\footnotetext{
60 Cfr., PIscione, P., Professioni (disciplina delle) voce, in "Enc. Dir. XXXVI", Milano 1987, pp. 1040 ss.

61 Cfr., Caia, F-Diana, A.G.-Pecorella, V., Codice Commentato della Deontologia Forense, UTET Giuridica, Lavis (TN) 2012.

62 Cfr., Perfetti, U., op. cit.
} 
a la que se refiere y que lleven a cabo, en el marco de la administración de justicia, condición que se encuentra en la misma fórmula ritual utilizada para los fines del juramento, donde queda el juramento expreso de cumplir con los deberes profesionales con lealtad, honor y diligencia. para los fines de la justicia y los mejores intereses de la nación.

Esta última parte del juramento ritual es útil para nuestros propósitos por duplicado, sea en relación con el concepto recordado de justicia sea en el de interés superior de la nación. El concepto de justicia, en este contexto, podría ser ese elemento útil para salir del empasse si consideramos la norma deontológica como jurídica o referible a la moral, en ese contraste entre derecho y moral que siempre surge como un dualismo jurídico entre derecho natural. y derecho positivo. En otras palabras, también en este caso nos encontramos con lacontraposición entre derecho y moral, afirmando en conclusión que la norma deontológica debe ser considerada jurídica, pasando por las distintas fases de la calificación de la regla de conducta de la categoría.

De hecho, partiendo de la concepción kelseniana antes mencionada de la legalidad del derecho sólo si se sitúa dentro del ordenamiento jurídico, no podemos permanecer indiferentes ni al problema del papel del abogado en el ejercicio de la profesión, ni a la calificación de la ley en cuestión. Baste analizar la fórmula ritual en la parte en que el abogado ejerce la profesión para el alto propósito de la justicia. La teoría que ve la norma deontológica como extrajurídica parece, en este punto, encontrar el mismo problema al que se enfrenta Kelsen cuando examina el concepto de justicia y se encuentra, ob torto collo, teniendo que lidiar con la moralidad, o más bien con la valores que subyacen a la idea misma de justicia. El concepto de justicia surge al mismo tiempo, como un problema jurídico y moral, de hecho dado que la doctrina de la justicia está en el centro de la acción, toda normatividad del actuar tiene un problema de lo justo. ${ }^{63}$ En este sentido, la noción de justicia se refiere a la idea de que las relaciones intersubjetivas deben ajustarse a un orden objetivo, tendiente a establecer y hacer cumplir las condiciones que hacen posibles las relaciones humanas. Esto es en consideración al hecho de que la justicia, concierne a los deberes que tenemos hacia los demás ${ }^{64}$, exactamente de la misma manera en que se comportan las normas deontológicas. Por tanto, si se afirma la justicia entre tener

\footnotetext{
63 Cfr., Gonella, G., Diritto e morale, Giuffrè, Milano 1960.

64 Cfr., Viola, F., Dalla natura ai diritti, Laterza, Roma-Bari 1997.
} 
una vida moral, entonces, podemos afirmar que está estrictamente relacionada tanto con la ley (orden en general) como con la moral ${ }^{65}$ (orden particular). Mismo fin entre lo general y lo particular, por lo que las normas deontológicas son fundamentales para la realización y protección de estos valores. ${ }^{66}$

\section{EL CÓDIGO DEONTOLÓGICO FORENSE EUROPEO}

Es importante observar cómo, en términos de clasificación de las normas deontológicas, se concluyó a favor de su definición, como normas jurídicas con capacidad vinculante propia, rastreando su origen en la disposición contemplada por la norma estatal. Este supuesto de "plena juridicidad" de las reglas deontológicas es argumentado por diversas sentencias jurisprudenciales, como el Tribunal de Casación italiano, motivando que, las reglas de conducta del profesional, expresadas por artículos 12, apartado 1 y 38 del Real Decreto de 1933, no constituyen más que prescripciones comparables a cláusulas generales, que, a su vez, se concretan en las normas del código deontológico, en la parte en la que, a raíz de abusos o faltas, tengan que incurrir los abogados en el ejercicio de la profesión, son objeto de expediente disciplinario, este último identificable como el poder atribuido al sistema profesional (que debe leerse también como poder normativo) y no diferido al legislador, cesando en este último caso la autonomía de los cuerpos profesionales.

Útil para este propósito es la pronunciación n. 189 de 2001 de la Corte de Justicia, que hizo referencia expresa al código deontológico forense, en cuanto a cómo dar el rumbo correcto al desempeño del mandato, a fin de justificar en los casos oportunos la forma correcta de llevar a cabo el mandato y, en casos reales, el ejercicio de la potestad disciplinaria por parte de los órganos profesionales.En este marco también se confirma en el Código deontológico forense espa$\tilde{n}_{0}{ }^{67}$, donde el preámbulo establece que "como toda ley, la deontología está incluida en el universo del derecho, regida por el principio de jerarquía normativa y exige además claridad, adecuación y precisión, de modo que cualquier cambio de hecho o de derecho en la situación regulada requiera que la regulación se adapte a la nueva realidad jurídica o social ".

\footnotetext{
65 Cfr., Helzel, P.B., Per una teoria generale del dovere, Cedam, Padova 2016.

66 Preambolo al codice di deontologia forense italiano.

67 Código deontológico del Colegio de Abogados de España, aprobado por el Colegio General del Colegio de Abogados de España el 6 de marzo de 2019.
} 
En esta perspectiva, se puede afirmar, por un lado, que su enunciado deja indicaciones precisas sobre los principios de carácter general que integran modelos de comportamiento (deontológicos), por otro lado, que su técnica de formulación para cláusulas generales requiere la posterior y necesaria fase de concretización del contenido del principio. Así, el código deontológico (norma deontológica autoproducida por el orden profesional) representaría el momento de la especificación del contenido y asumiría valor vinculante (fuente del precepto y justificación de su juridicidad) por la relación que se instaura entre éste y las cláusulas generales. Calificadas las normas deontológicas como normas internas, la solución al problema viene dada por la forma en que se establece la relación entre los dos sistemas y, por tanto, subsistirá el carácter normativo de los fijados por el sistema sectorial cuando éste sea establecido por el sistema de las normas sobre la formación del ordenamiento estatal. Disposición que no surge para el ordenamiento de los abogados. ${ }^{68}$

Al respecto, el Tribunal de Casación pudo aclarar, con la sentencia conjunta núm. 26810 de 20 de diciembre de 2007, los principios según los cuales los consejos de ley, territorialmente competentes, ejercen funciones administrativas aun cuando actúen en materia disciplinaria, respecto de la actividad del Consejo Nacional Forense que, cuando se pronuncia sobre la misma materia, es un órgano jurisdicional y más precisamente, un juez especial preconstitucional, que examina la relación que se establece entre el derecho estatal y las normas sectoriales propias del ordenamiento forense. Según los jueces de la Corte, estas últimas son normas jurídicas y este carácter deriva de la delegación que les confiere la ley estatal y de la función de parámetro normativo general a partir de la cual evaluar la conducta de los profesionales registrados. Asumen, en esencia, una función integradora de la legislación en blanco sobre la referencia expresa del legislador a la autonomía colectiva.

A juicio del tribunal, la norma deontológica debe definirse como una norma jurídica $y$, en consecuencia, directamente interpretable en términos de legitimidad como las demás normas, ya que de lo contrario este canon interpretativo, de legitimidad, quedaría excluido del tribunal en caso de que las normas deontológicas no pueden calificarse de jurídicas, pues "Las reglas del código deontológico forense constituyen fuentes normativas complementarias del precepto legislativo, que atribuye al Consejo nacional forense la facultad de reglamentar, con la función de jurisdicción especial

68 Cfr., Perfetti, U., op. cit. 
perteneciente al sistema general del Estado, como tal interpretable directamente por el tribunal de legitimidad"69. En otros términos, los preceptos normativos sectoriales dictados por el código deontológico, no son normas extra jurídicas, sino fuentes de una jurisdicción especial que sin embargo mantiene un vínculo firme con el ordenamiento general. Este último atribuye las competencias al Consejo Nacional Forense y de legislar y ejercer la actividad judicial contra los integrantes de la categoría.

Este vínculo y la calificación de las normas jurídicas de los deberes profesionales, permite someter al escrutinio de los jueces del Tribunal de Casación la legitimidad de las reglas deontológicas. Conforme a esta interpretación está siempre la Corte Suprema de Casación, la cual recientemente, en las Secciones Unidas (sentencia núm. 8313\2019) volvió a dictaminar que "las disposiciones del código deontológico forense tienen en realidad el carácter de una fuente meramente complementaria de los preceptos regulatorios y pueden legítimamente inspirarse en conceptos difundidos y generalmente comprendidos por la comunidad. De ello se desprende que, con el fin de garantizar el derecho de defensa del abogado imputado en la etapa disciplinaria, es necesario que se impugne la conducta adscrita como integrante de la violación deontológica y no la nomen iuris o el título de la infracción de retención: el juez disciplinario es libre de identificar la configuración exacta de la infracción tanto en cláusulas generales como en diversas reglas deontológicas o incluso reconocer un hecho disciplinariamente relevante en una conducta atípica no prevista por dichas reglas (Cass., sección primera, 7 de julio de 2009, no. 15852; 17 de enero de 2012, no. 529; 17 de marzo de 2017, no. 6967) “.

El mismo Código Deontológico de la Abogacía Europea se ocupa, en el preámbulo, de matizar la naturaleza de las normas deontológicas, que tienen por objeto garantizar, a través de su libre aceptación por parte de quienes se aplican, el correcto cumplimiento por parte del defensor de su función, reconocida como indispensable para el buen funcionamiento de toda la sociedad humana. El incumplimiento por parte del abogado de estas reglas puede dar lugar a sanciones disciplinarias. Cada orden forense tiene sus propias reglas específicas, que son fruto de sus tradiciones. Tales normas se adaptan en función de la organización y el sector de actividad de la abogacía dentro del ámbito del Estado miembro en cuestión, así como de los procedimientos judiciales y

69 Cassazione Sezioni Unite n. $26810 \backslash 2007$. 
administrativos y de la legislación nacional. No es posible ni deseable extraerlos de su contexto ni intentar generalizar normas que no pueden ser generalizadas. ${ }^{70}$

Los Códigos Deontológicos establecen, por tanto, las reglas de conducta que el profesional, en relación al rol que desempeña dentro de la sociedad, está obligado a observar en general y, en concreto, en sus relaciones con todos los sujetos con los que entabla relación. Asimismo, a través del cumplimiento de dichas normas de conducta, el profesional contribuye a la protección de los principios que sustentan el Estado de derecho y la sociedad democrática. ${ }^{71}$

$70 \quad$ Art. 1.2. Preámbulo del Código Deontológico de los Abogados Europeos.

71 Por ejemplo, en el preámbulo del Código deontológico forense español se afirma que "La Abogacía ha depurado valores salvaguardados por normas éticas necesarias no solo para el derecho a la defensa, sino también para la protección de los más altos intereses del Estado, hoy proclamado social y democrático por ley ". 